\title{
ENGINEERING PROPERTIES OF DEBRIS FLOW MATERIAL AT BUNDU TUHAN, RANAU, SABAH, MALAYSIA
}

\author{
Edgar Jr. Joe ${ }^{1,2}$, *, Felix Tongkul2,3, Rodeano Roslee ${ }^{2,3}$ \\ ${ }^{1}$ Slope Branch, Public Works Department of Sabah, Kota Kinabalu, Sabah, Malaysia. \\ ${ }^{2}$ Faculty of Science and Natural Resources, Universiti Malaysia Sabah, Kota Kinabalu, Sabah, Malaysia. \\ ${ }^{3}$ Natural Disaster Research Centre, Kota Kinabalu, Sabah, Malaysia.. \\ *Corresponding author's email: Edgar.Joe@sabah.gov.my
}

This is an open access article distributed under the Creative Commons Attribution License, which permits unrestricted use, distribution, and reproduction in any medium, provided the original work is properly cited.

\section{ARTICLE DETAILS}

\section{Article History:}

Received 26 June 2018

Accepted 2 July 2018

Available online 1 August 2018

\section{ABSTRACT}

Recurring events of debris flow especially during heavy rainfall have caused cut-off at one of the main road in Bundu Tuhan, Ranau namely Jalan Tamparuli-Ranau KM 83.90. In several incidents, the road was closed to public for hours due to deposition of thick sediment on the road, causing interruption to their daily activities. However, study on the properties of the debris flow material and their relationship with debris flow characteristics is quite limited. Thus, the objective of this study is to comprehend the debris flow trait based on the material property. The study of the material property pertains to the grain size distribution, Atterberg limit, and lastly the moisture content. They are interpreted based on the results in site investigation report where the soil samples were taken from nine numbers of trial pits which were excavated around the runout and deposition zones. This study found that the granular type debris flow displays high kinetic energy, shorter transportation distance towards deposition, large velocity, and more sediment flow towards deposition. Meanwhile, the low plasticity index of the soil causes a high occurrence of liquefaction process. Higher moisture content has also assisted in the mobilization of material.

\section{KEYWORDS}

Debris flow, engineering, material, property.

\section{INTRODUCTION}

Several incidents of debris flow have occurred at Bundu Tuhan area in the district of Ranau. One of the notable occurrences was that at the main road of Jalan Tamparuli-Ranau KM 83.90. The debris flows have been recurring from the 2012 until 2014 which rendered the road impassable to traffic for hours and caused many nuisances to the public. Thick material including loose soil, fragmented rock, and de-rooted trees were deposited on the road. Nevertheless, study on the material properties and their relationship with the debris flow characteristic is lacking. In the previous studies, researchers have attempted to identify the relationship between the engineering properties of material and debris flow traits. Some of the current parametric studies emphasizes on grain size, plasticity index, and moisture content. Larger mean grain size and coarser particle will increase the kinetic energy of debris flow, while well-sorted material will cause longer travel distance and carry less sediment [1]. On the other hand, higher fine grain content will assist to mobilize the sediment as it can float at ease and maintain high pore pressure during the flow [2]. Meanwhile, the Atterberg limit can be simply defined as the comparative easiness in which the soil may deform and indicates the consistency degree of the soil [3]. In a soil with low plasticity index where the range between the plastic limit and liquid limit is small, the sediment may quickly change from semi solid to liquid state. This may cause huge decrease in the cohesion and angle of internal friction which can lead to slope instability [4]. A group of researchers added that the liquefaction rate for soil mainly composed of sand and silt are higher compared to that with clay [5]. The liquefaction is also greatly influenced by the low plasticity soil. Other studies have identified that the increase in soil moisture content may contribute to debris flow occurrence by the development of pore pressure in the soil $[4,6]$.
The authors stated that the moisture content can be mainly altered either by prolong rainfall or rise in ground water level. Deformation in the soil can be observed when the moisture content exceeds the plastic limit [3].

\section{STUDY AREA}

The study area at Jalan Tamparuli-Ranau KM 38.80 is situated in Bundu Tuhan area within the district of Ranau. As part of the major routes between the west coast and east coast of the state, the road provides a crucial link amongst towns such as Tuaran, Tamparuli, Kundasang, and Ranau. Geographically, it is positioned at a latitude of $6^{0} 00^{\prime} 40^{\prime \prime} \mathrm{N}$ to $6^{0} 01^{\prime} 00^{\prime \prime} \mathrm{N}$ and longitude of $116^{0} 30^{\prime} 20^{\prime \prime} \mathrm{E}$ to $116^{0} 30^{\prime} 40^{\prime \prime} \mathrm{E}$. About $85 \mathrm{~m}$ long and $20 \mathrm{~m}$ wide road section is affected due to debris flow. The study area covers the distance of $0.23 \mathrm{~km}$ from north to south and $0.30 \mathrm{~km}$ from west to east. Geologically, the site is underlain by the Crocker Formation of Eocene-Oligocene age which comprised of sedimentary rock units of interbedded sandstone and shale. 


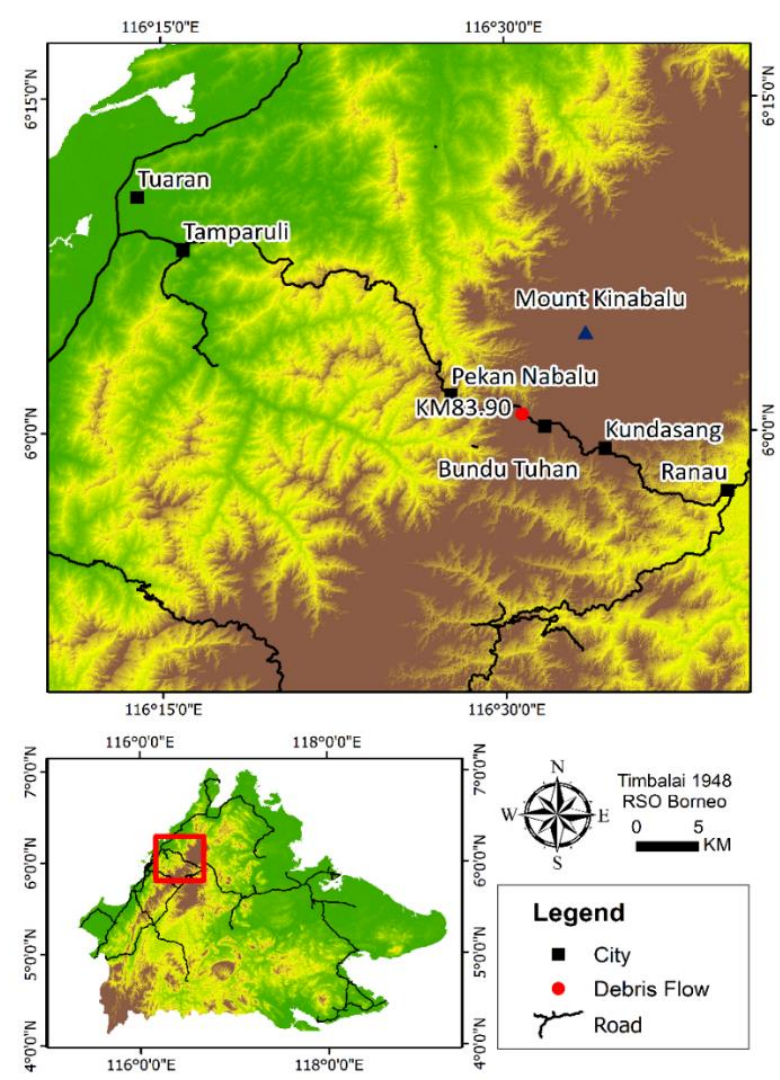

Figure 1: Location of study area at Jalan Tamparuli-Ranau KM 83.90, Bundu Tuhan, Ranau.

The worst debris flow incident at Jalan Tamparuli-Ranau KM 83.90 has occurred on $6^{\text {th }}$ May 2012 as shown in Photograph 1. The road was impassable to traffic for more than five hours due to deposition of about 5 $m$ thick sediment on road. Most of the incidents happened during evening and night time which pose high risk to the road commuters.

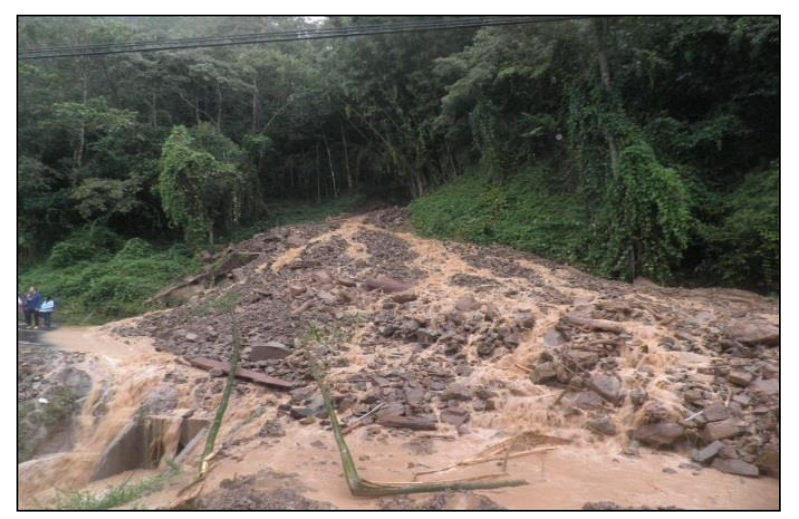

Photo 1: Debris flow at Jalan Tamparuli-Ranau KM 83.90 on $6^{\text {th }}$ May 2012

\section{METHODOLOGY}

The material property was analysed in reference to the result of particle size distribution, Atterberg limit, and soil moisture content in the site investigation (SI) report.

The particle size distribution was done based on sampling of material at drilled borehole (BH) and excavated Trial Pit (TP) at the study areas as interpreted from the SI report. Four numbers of BH were sunk and nine numbers of TP were excavated at the study area (Figure 2). BH 2 to BH 4 and TP 4 to TP 9 were situated within the runout area while the rest were around the deposition zone. Four parameters of grain size were analysed to identify the relationship between the material property and the flow behaviour in terms of velocity, discharge, and travel distance. The four parameters are mean grain size, standard deviation, coefficient of skewness, and coefficient of kurtosis.
Prior to the calculation of the parameters, percentage passing was plotted against particle size on a semi-log graph. The particle sizes were divided into gravel $(2-63 \mathrm{~mm})$, sand $(0.063-2 \mathrm{~mm})$, silt $(0.002-0.063 \mathrm{~mm})$, and clay $(<0.002 \mathrm{~mm})$.

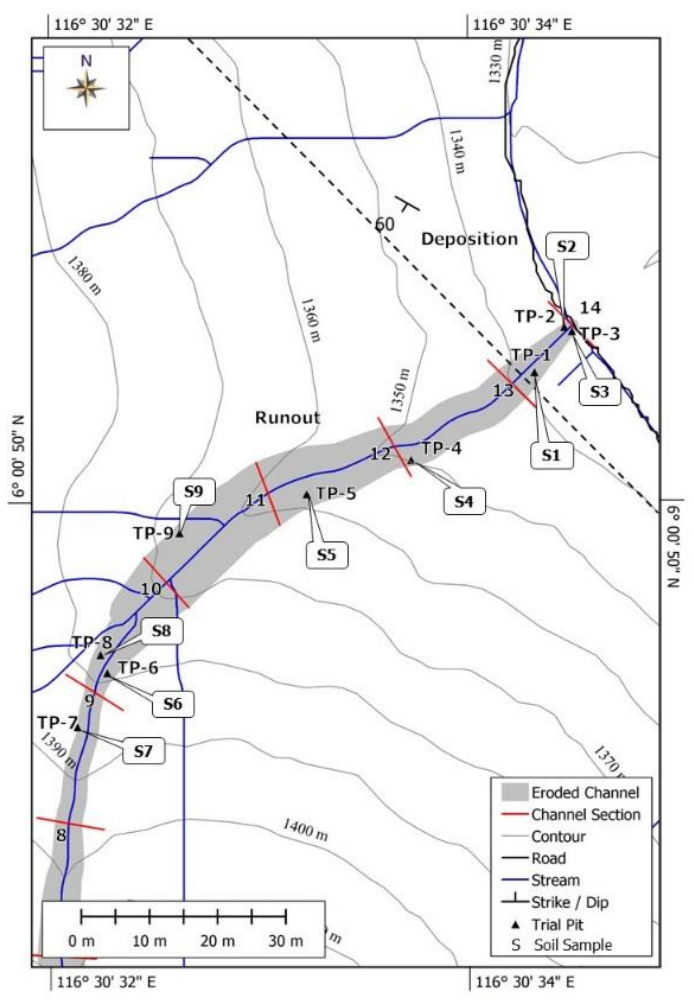

Figure 2: Location of soil sample at Jalan Tamparuli-Ranau KM 83.90.

The mean grain size can be defined as the average diameter of a particle within a sample and expressed as in equation 1 [7].

$$
M=\frac{\emptyset_{16}+\emptyset_{50}+\emptyset_{84}}{3}
$$

where $M$ is mean grain size (mm); $\emptyset_{16}$ is grain size at $16 \%$ percentage passing $(\mathrm{mm}) ; \emptyset_{50}$ is grain size at $50 \%$ percentage passing $(\mathrm{mm})$; and $\emptyset_{84}$ is grain size at $84 \%$ percentage passing $(\mathrm{mm})$.

The standard deviation shows the variation degree based on mean grain size. Data points that are closer to the mean signifies a low standard deviation, whereas a large range of values indicated a high standard deviation [1]. It is expressed by equation 2 .

$$
\sigma=\frac{\emptyset_{84}-\emptyset_{16}}{4}+\frac{\emptyset_{95}-\emptyset_{5}}{6.6}
$$

where $\sigma$ is standard deviation; $\emptyset_{5}$ is grain size at $5 \%$ percentage passing $(\mathrm{mm}) ; \emptyset_{16}$ is grain size at $16 \%$ percentage passing $(\mathrm{mm}) ; \emptyset_{84}$ is grain size at $84 \%$ percentage passing $(\mathrm{mm})$; and $\emptyset_{95}$ is grain size at $95 \%$ percentage passing $(\mathrm{mm})$.

Based on the standard deviation, the degree of sorting can be checked from Table 1.

Table 1: Gradation standard of the degree of sorting according to the standard deviation [7].

\begin{tabular}{|c|c|}
\hline Standard Deviation & Degree of Sorting \\
\hline$<0.35$ & Extremely good \\
\hline $0.35-0.5$ & Good \\
\hline $0.5-0.71$ & Fair \\
\hline $0.71-1$ & Medium \\
\hline $1-2$ & Poor \\
\hline $2-4$ & Very poor \\
\hline$>4$ & Extremely poor \\
\hline
\end{tabular}


The coefficient of skewness represents the symmetry degree of coarse and fine grains in the curve of distribution with respect to the modal value location. A coarse-grain side is skewed to a positive direction while the latter is vice versa [7]. The coefficient is given by equation 3 .

$$
S K=\frac{\emptyset_{16}+\emptyset_{84}-2 \emptyset_{50}}{2\left(\emptyset_{84}-\emptyset_{16}\right)}+\frac{\emptyset_{5}+\emptyset_{95}-2 \emptyset_{50}}{2\left(\emptyset_{95}-\emptyset_{5}\right)}
$$

where $S K$ is coefficient of skewness; $\emptyset_{5}$ is grain size at $5 \%$ percentage passing (mm); $\emptyset_{16}$ is grain size at $16 \%$ percentage passing $(\mathrm{mm}) ; \emptyset_{50}$ is grain size at $50 \%$ percentage passing $(\mathrm{mm}) ; \emptyset_{84}$ grain size at $84 \%$ percentage passing (mm); and $\emptyset_{95}$ grain size at $95 \%$ percentage passing $(\mathrm{mm})$.

The gradation of skewness is given in Table 2 .

Table 2: Skewness gradation [7].

\begin{tabular}{|c|c|}
\hline Coefficient of Skewness & Skewness \\
\hline$[-1.00,-0.3)$ & Extremely negative \\
\hline$[-0.3,-0.1)$ & Negative \\
\hline$[-0.1,+0.1)$ & Symmetrical \\
\hline$[+0.1,+0.3)$ & Positive \\
\hline$[+0.3,+1.0)$ & Extremely positive \\
\hline
\end{tabular}

The coefficient of kurtosis is a measure of peakedness or flatness in a distribution. A wider distribution is represented by smaller kurtosis coefficient, whereas as bigger kurtosis coefficient indicates narrower particle distribution [7]. The kurtosis coefficient is given by equation 4 .

$$
K g=\frac{\emptyset_{95}-\emptyset_{5}}{2.44\left(\emptyset_{75}-\emptyset_{25}\right)}
$$

where $\mathrm{Kg}$ is coefficient of kurtosis; $\emptyset_{5}$ is grain size at $5 \%$ percentage passing $(\mathrm{mm}) ; \emptyset_{25}$ is grain size at $25 \%$ percentage passing $(\mathrm{mm}) ; \emptyset_{75}$ is grain size at $75 \%$ percentage passing $(\mathrm{mm})$; and $\emptyset_{95}$ is grain size at $95 \%$ percentage passing $(\mathrm{mm})$.
The kurtosis coefficient indicates form of curve as explained in Table 3.

Table 3: Kurtosis gradation [7].

\begin{tabular}{|c|c|}
\hline Coefficient of Kurtosis & Form of Curve \\
\hline$<0.67$ & Very wide and gentle \\
\hline $0.67-0.90$ & Wide and gentle \\
\hline $0.90-1.11$ & Medium \\
\hline $1.11-1.56$ & Narrow and sharp \\
\hline $1.56-3.00$ & Very narrow and sharp \\
\hline$>3.00$ & Extremely narrow and sharp \\
\hline
\end{tabular}

The plasticity of the material was analyzed based on the result of Atterberg limits test in the SI report. For this purpose, the plasticity index which is defined as the range of moisture content where the soil exhibits plastic properties were computed using equation 5 [8].

$$
P I=L L-P L
$$

where $P I$ is plasticity index; $L L$ is liquid limit; and $P L$ is plastic limit.

As the change of moisture content in the sediment material will govern the behaviour of debris flow, the range of moisture content is studied based on the laboratory testing result in the SI report. The moisture content is defined as the ratio of weight of water to the weight of soil solid and expressed as in equation 6 [8].

$$
w=\frac{w_{l}}{w_{d}} \times 100
$$

where $w$ is moisture content of soil (\%); $w_{l}$ is weight of water (g); and $w_{d}$ is weight of soil solid (g).

\section{RESULT AND DISCUSSION}

The results of the laboratory testing which pertain to the particle size

\begin{tabular}{|c|c|c|c|c|c|c|c|c|c|c|}
\hline \multirow{2}{*}{ TP } & \multirow{2}{*}{$\begin{array}{c}\text { TP } \\
\text { Sample }\end{array}$} & \multirow{2}{*}{$\begin{array}{c}\text { Sample } \\
\text { No. }\end{array}$} & \multicolumn{4}{|c|}{ Particle Size Distribution (\%) } & \multicolumn{3}{|c|}{ Atterberg Limits (\%) } & \multirow{2}{*}{$w(\%)$} \\
\hline & & & Gravel & Sand & Silt & Clay & $L L$ & $P L$ & $P I$ & \\
\hline 1 & BS1 & 1 & 51 & 35 & 12 & 2 & 10.0 & 5.3 & 4.7 & 5.27 \\
\hline 2 & BS2 & 2 & 43 & 38 & 17 & 2 & 17.3 & 13.0 & 4.3 & 12.99 \\
\hline 3 & BS3 & 3 & 44 & 34 & 19 & 3 & 17.3 & 13.9 & 3.4 & 13.92 \\
\hline 4 & BS4 & 4 & 40 & 42 & 14 & 4 & 23.0 & 19.9 & 3.1 & 19.93 \\
\hline 5 & BS5 & 5 & 40 & 44 & 14 & 2 & 29.0 & 23.9 & 5.1 & 23.88 \\
\hline 6 & BS6 & 6 & 49 & 31 & 18 & 2 & 36.5 & 31.2 & 5.3 & 31.16 \\
\hline 7 & BS7 & 7 & 45 & 33 & 18 & 4 & 40.0 & 35.5 & 4.5 & 35.48 \\
\hline 8 & BS8 & 8 & 62 & 26 & 10 & 2 & 28.0 & 23.7 & 4.3 & 23.71 \\
\hline 9 & BS9 & 9 & 41 & 37 & 18 & 4 & 27.5 & 24.4 & 3.1 & 24.39 \\
\hline
\end{tabular}
distribution, Atterberg limits and soil moisture content are summarized in Table 4 as follows.

Table 4: Summary of laboratory testing results for soil samples at Jalan Tamparuli-Ranau KM 83.90 [9].

\subsection{Particle Size Distribution}

The particle size distribution in Table 4 shows that the debris flow material consisted of $40 \%$ to $62 \%$ gravel, $26 \%$ to $44 \%$ sand, $10 \%$ to $19 \%$ silt, and $2 \%$ to $4 \%$ clay. In average, the debris flow is predominantly composed of coarser material ( $82 \%$ of gravel and sand) with silty sand soil type. Next, the particle size curve is plotted in Figure 3. The curve shows a well-graded type of soil, in which the particles are distributed over a wide range.

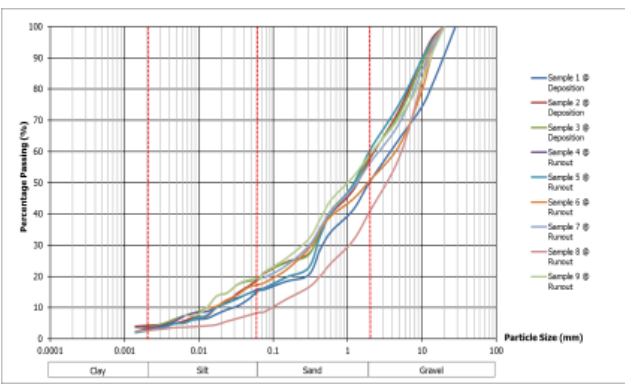

Figure 3: Particle size distribution of soil sample at Jalan TamparuliRanau KM 83.90. 
Grain diameter in the particle distribution chart is then analysed to calculate grain size parameter pertaining to mean grain size, standard deviation, coefficient of skewness, and coefficient of kurtosis. The result as shown in Table 5 is explained as follows:

a. The mean grain size ranges between $0.82 \mathrm{~mm}$ and $5.21 \mathrm{~mm}$. The larger grain size shows that the debris flow is able to mobilize bigger sediment which requires higher kinetic energy.

b. The range of the standard deviation lies between 2.50 and 7.01. Thus, very poor and extremely poor degrees of sorting have happened towards the deposition zone. This type of sorting has posed shorter transportation distance which finally causes halt in the material mobilization.

c. The coefficient of skewness is as low as 0.66 and as high as 0.98 . This indicates extremely positive skewness gradation of the sedimentation and larger grain diameter. Thus, larger velocity in the flow has transported the big grain size.

d. The coefficient of kurtosis ranges from 0.80 to 3.31. Most of the soil samples (about 33\%) in the runout zone pertain to narrow and sharp kurtosis gradations which represent a better degree of sorting, longer transportation distance, and less sediment carried by the flow.

Table 5: Grain size parameter based on grain diameter at Jalan Tamparuli-Ranau KM 83.90.

\begin{tabular}{|c|c|c|c|c|c|c|c|c|c|c|c|}
\hline \multirow{2}{*}{ Sample } & \multicolumn{7}{|c|}{ Grain Diameter (mm) } & \multicolumn{4}{|c|}{ Soil parameter } \\
\hline & $\phi_{5}$ & $\phi_{16}$ & $\phi_{25}$ & $\phi_{50}$ & $\phi_{75}$ & $\phi_{84}$ & $\phi 95$ & $M$ & $\sigma$ & $S K$ & $K g$ \\
\hline $1 @$ Depo & 0.00 & -0.02 & 0.32 & 1.90 & 9.41 & 13.76 & 23.55 & 5.21 & 7.01 & 0.78 & 1.06 \\
\hline $2 @$ Depo & 0.00 & 0.04 & 0.17 & 0.52 & 1.57 & 6.76 & 11.25 & 2.44 & 3.38 & 0.88 & 3.31 \\
\hline $3 @$ Depo & 0.00 & 0.02 & 0.27 & 0.12 & 2.94 & 7.93 & 14.05 & 2.69 & 4.11 & 0.98 & 2.15 \\
\hline $4 @$ R0 & 0.00 & 0.06 & 0.25 & 0.15 & 4.87 & 6.61 & 12.57 & 2.27 & 3.54 & 0.98 & 1.12 \\
\hline $5 @$ R0 & 0.01 & -0.03 & 0.25 & 0.14 & 4.89 & 6.53 & 12.72 & 2.21 & 3.57 & 0.96 & 1.12 \\
\hline $6 @$ R0 & -0.03 & 0.04 & 0.22 & 1.80 & 8.57 & 7.89 & 16.22 & 3.24 & 4.43 & 0.66 & 0.80 \\
\hline 7 @ R0 & -0.20 & 0.01 & 0.20 & 0.53 & 4.36 & 9.09 & 15.48 & 3.21 & 4.65 & 0.90 & 1.54 \\
\hline $8 @$ @O & 0.02 & 0.28 & 0.63 & 0.52 & 7.63 & 1.64 & 14.26 & 0.82 & 2.50 & 0.79 & 0.83 \\
\hline $9 @$ RO & 0.64 & 0.02 & 0.13 & 0.98 & 6.33 & 8.18 & 16.31 & 3.06 & 4.41 & 0.86 & 1.04 \\
\hline
\end{tabular}

\section{Note:}

$\mathrm{RO}=$ Runout; Depo=Deposition; $\phi_{\mathrm{n}}=$ Grain diameter at $\mathrm{n}$ percentage passing; $\mathrm{M}=$ Mean grain size; $\sigma=$ Standard deviation; SK = coefficient of skewness; Kg = coefficient of kurtosis

\subsection{Atterberg Limit}

The fine-grained soil samples contain low plasticity index between $3.1 \%$ and $5.3 \%$ (Table 4). They are mainly classified as silt with low plasticity, which pertain to $78 \%$ of the soil samples as shown in the Plasticity Index chart (Figure 4). As presented by the low plasticity index, the material of debris flow may rapidly alter from its plastic state to the liquid state upon adequate infiltration of water content from the upper reach of the channel. This shall later promote the mobilization of the debris flow to further extent of travel distance.

As stated in a study, the liquefaction process contributes to transformation of landslide into debris flow and assists in the mobilization of the debris flow [10]. The low plasticity index of the soil samples represent a higher occurrence of liquefaction process in the debris flow sediment, which controlled by the silt particles.

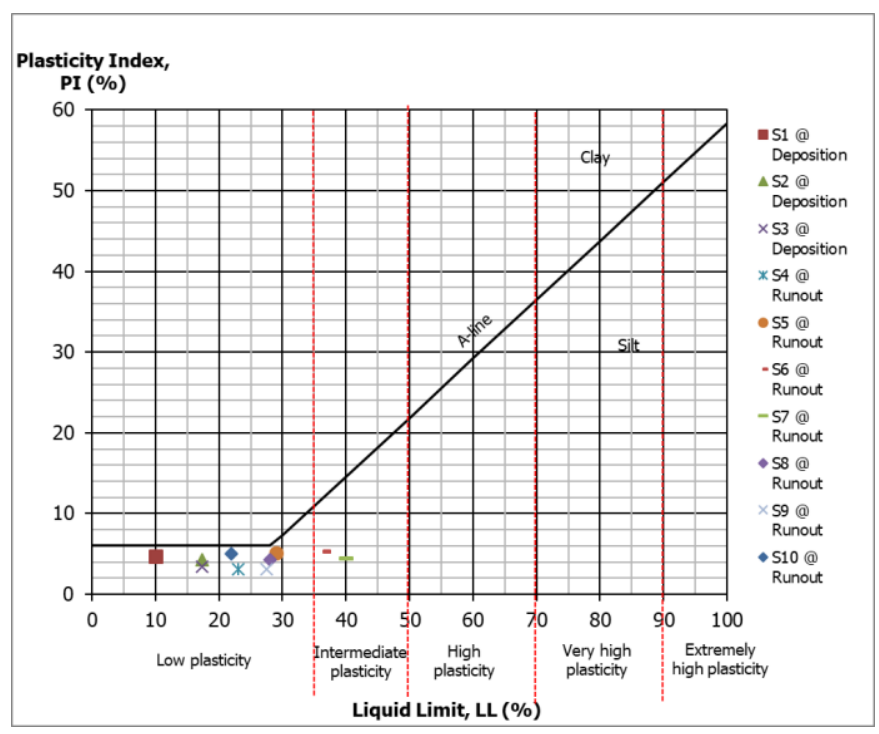

Figure 4: Plasticity Index chart of soil sample at Jalan Tamparuli-Ranau KM 83.90.

\subsection{Moisture Content}

The moisture content of the soil sample ranges from $5.27 \%$ to $35.48 \%$. All of the soil samples show moisture content of at least equivalent to the plastic limit. Therefore, very small increase of moisture content of about $1 \%$ for this site due to external factor such as rainfall is sufficient to exceed the plastic limit where the soil starts to deform or initiation of debris flow takes place.

\section{CONCLUSION}

In conclusion, the granular type debris flow displays high kinetic energy, shorter transportation distance towards deposition, large velocity, and more sediment flow towards deposition. In terms of mobilisation, the low plasticity index of the soil causes a high occurrence of liquefaction process, which is coupled with higher moisture content. The engineering property of debris flow material is interpreted based on available SI report. As the soil samples were only taken along the runout and deposition zone, analysis of material property at the initiation zone was not carried out. Therefore, future study should consider the relationship between the material property at initiation zone and the debris flow occurrence. However, this suggestion will depend on the site accessibility for soil sample collection.

\section{REFERENCES}

[1] Wen, Z., Qing, W., Jianping, C., Huizhong, L., Jinsheng, Q. 2015. Grainsize analysis of debris flow alluvial fans in Panxi area along Jinsha River, China. Sustainability, 7, 15219-15242.

[2] Chao, M., Yu-jie, W., Cui, D., Yun-qi, W., Yun-peng, L. 2016. Variation in initiation condition of debris flows in the mountain regions surrounding Beijing. Geomorphology, 273, 323-334.

[3] Bidyashwari, H., Kushwaha, R., Chandra, M., Okendro, M. 2017. Physical properties of soil and its implication to slope stability of Nungbi Khunou, NH-150, Manipur. International Journal of Geosciences, 8, 1332-1343.

[4] Yalcin, A. 2007. The effects of clay on landslides: A case study. Science Direct, 38, 77-85. 
[5] Ige, O., Oyeleke, T., Baiyegunhi, C., Oloniniyi, T., Sigabi, L. 2016. Liquefaction, landslide and slope stability analyses of soils: A case study of soils from part of Kwara, Kogi and Anambra states of Nigeria. Natural Hazards and Earth System Sciences.

[6] Gusman, M., Nazki, A., Putra, R. 2018. The modelling influence of water content to mechanical parameter of soil in analysis of slope stability. Journal of Physics, 1008.

[7] Folk, R.L., Ward, W.C. 1957. Brazos River Bar: Study in the significance of grain size parameters. Journal of Sedimentary Petrology, 27 (1), 3-26.
[8] British Standard Institution. 1999. BS 5930: 1999 (Code of practice for site investigations). British Standard Institution.

[9] Borneo Jadi Drilling Enterprise. 2015. Site Investigation Report for KM 83.90 Jalan Kota Kinabalu-Sandakan (Laluan Persekutuan 22). Kota Kinabalu: (unpublished).

[10] Takahashi, T. 2007. Debris flow: Mechanics, prediction, and countermeasures. London: Taylor \& Francis Group.

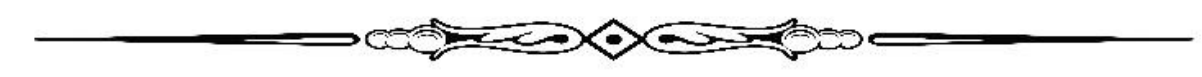

